\title{
Evaluation of Shearing Time Sufficient for Effective Liquid Metal Processing
}

\author{
AGNIESZKA DYBALSKA ${ }^{1,2,3}$ DMITRY ESKIN,${ }^{1}$ and JAYESH B. PATEL ${ }^{1}$ \\ 1.-BCAST, Brunel University London, Uxbridge UB8 3PH, UK. 2.—e-mail: dybalska.ag@gmail.com. \\ 3.—e-mail: gaielle@wp.eu
}

\begin{abstract}
Melt shearing has been suggested to be an efficient means of structure refinement through oxide dispersion and fragmentation. One of the process parameters that needs to be optimized is the shearing time. In this paper, the effect of shearing time on alumina powder refinement was studied in a model system with water as a working fluid. The established time was taken as a first approximation for experiments with the liquid metals processing by a high shear device based on a rotor-stator technology. The water model findings were confirmed experimentally on liquid aluminum alloys, and indicate that the optimal time of mixing is equal to 4 min in fully agitated conditions for the volume of $2.7 \mathrm{dm}^{3}$.
\end{abstract}

\section{INTRODUCTION}

The removal of harmful oxide films from aluminum melts has been a key research field for many years, as their formation is unavoidable. In recent years, an alternative way of tackling this issue has been suggested, i.e. breaking the films into small fragments or particles instead of removing them from the liquid metals. ${ }^{1,2}$ This is done by intensive melt shearing using a stator-rotor device. Usually, entrained oxides and films are distributed nonuniformly in the melt. They are frequently large, folded and have a poor wettability. Thus, the naturally present oxide films are harmful as they facilitate porosity and cracking. ${ }^{3-6}$ It is possible to change this situation by a mechanical breakage of clusters or films and the dispersion of them into the liquid metal. Potentially, oxides (wet and dispersed) may act as good nucleating substrates for aluminum and magnesium. ${ }^{7-10}$

The Brunel Centre for Advanced Solidification Technology (BCAST) have proposed to realize this by using a high-shear mixer (HSM; Fig. 1b). During the intensive melt shearing, fragmentation of the oxide films as well as dispersion of individual oxide particles occurs. Finally, after processing by the HSM, they can play the role of nuclei in the nucleation process. The effect of melt shearing was a reduction in grain size, as reported by the BCAST team. ${ }^{11-14}$
The best processing conditions are, however, still not established. In this paper, we aim to find the best HSM processing time for aluminum and magnesium alloys using a water model with validation on an aluminum alloy.

\section{MATERIALS AND METHODS}

To check the influence of processing time on the alumina powder fragmentation, a number of experiments were required in a model system with about $1 \mathrm{~L}$ of water. As the viscosity of water at room temperature is similar to liquid aluminum and both are Newtonian fluids, water can mimic the aluminum flow behavior and is often used as a modeling material (i.e. Refs. 15-18). The HSM was immersed to about $20 \mathrm{~mm}$ above the bottom of the cylindrical vessel. The stator had 48 round holes arranged uniformly in 4 rows with $15^{\circ}$ angular difference in the hole positions between the rows. Alumina powder $\left(2 \mathrm{~cm}^{3}\right)$ of the initial rounded average size of $165 \pm 30 \mu \mathrm{m}$ was added to the distilled water. The rotational speed $(N)$ of the HSM was controlled and kept at a maximum level (9000 rpm). After a chosen time, the powder was collected by filtering and later cold-mounted into transparent epoxy resin. To improve visibility, the samples were ground and, after shearing, we could observe different fragments of broken alumina granules. To find the particle size distribution, we measured at least 200 observed areas of the broken particles. 


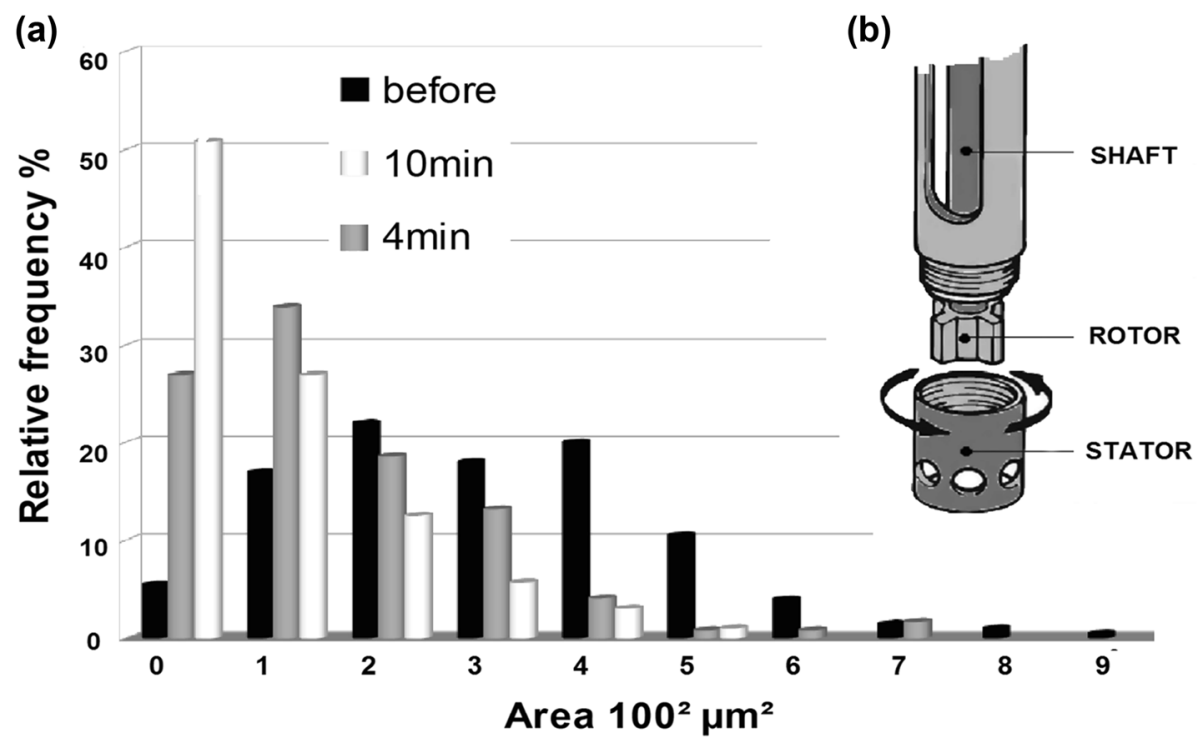

Fig. 1. (a) The histogram of the FDPA of the alumina before and after shearing by the HSM. (b) The HSM diagram.

The validation of the water experiments were done by shearing a prepared $\mathrm{Al}-3 \% \mathrm{Mg}$ binary alloy at $660^{\circ} \mathrm{C}$ (above the alloy liquidus). The ceramic mixer suitable for the metal processing with $N$ equal $3000 \mathrm{rpm}$ has an outside diameter of $42 \mathrm{~mm}$ while the rotor diameter was $32 \mathrm{~mm}$. The stator holes were round and arranged in rows. To avoid a temperature change, the crucible holding $2.7 \mathrm{dm}^{3}$ of the melt was placed in a heater. To examine the effect of HSM processing on the structure, the Aluminium Association Test Procedure-1 (TP-1) mold was used. The samples for metallography were cut at $50 \mathrm{~mm}$ above the bottom of a TP-1 casting and ground, polished and anodized to reveal the grain structure. Prepared metal samples, as well as mounted powders, were examined in a Zeiss microscope equipped with image analysis software. The grain size was measured by a conventional random intercept method with statistical analysis of the data.

\section{RESULTS AND DISCUSSION}

\section{Alumina Shearing in a Water Model}

The density difference between alumina and water is different from that of alumina and liquid aluminum. The alumina powder behaves as "heavier" particles in the water than in the liquid aluminum because of the higher density differences between the solid and liquid phases. Thus, we used the maximum speed of the motor and different processing times in a range of up to $10 \mathrm{~min}$. The time choices were based on our previous observations. The processing of the hard alumina powder by HSM causes a loud noise. In our experiment, the noise disappears after about $3 \mathrm{~min}$, apparently because the size of the particles becomes finer and they move smoothly through the head. By varying the processing time, we were able to observe the progress of the fragmentation process. Table I and Fig. 1 present the observed results of the frequency distribution of particles area (FDPA) of alumina sheared for $4 \mathrm{~min}$ and $10 \mathrm{~min}$ against the FDPA of non-sheared powder.

Longer processing (10 $\mathrm{min})$ of alumina (see Fig. 1a) improves the results of shearing especially in the range below $10,000 \mu \mathrm{m}^{2}$. In particular, the range of $0-5000 \mu \mathrm{m}^{2}$ contained over $67 \%$ of the measured sizes after a 10 -min shearing against $42 \%$ of particles found after $4 \mathrm{~min}$ of shearing. This difference was not very significant as the processing time was over 2 times longer. During $4 \mathrm{~min}$ of shearing, the number of particles with the area of up to $10,000 \mu \mathrm{m}^{2}$ increased from $22.5 \%$ to $60.8 \%$ (about 10\% per min). Next, the 6 min of mixing increased this number to $77.7 \%$ (about $3 \%$ per min). These results indicate that the process of particle refinement is much faster at the beginning and later slows down. This is consistent with the theory, ${ }^{19}$ since the number of agglomerates should decrease during the HSM processing up to the moment when almost all the clusters are broken (in an ideal situation). These experiments are the first direct evidence that intense liquid shearing may result in the fragmentation of hard and strong ceramic particles. The time dependence observed in this physical modeling cannot, however, be directly used to estimate the optimum shearing time for the oxide fragmentation in metallic melts. The shear forces which should effectively disperse oxides into the melts are much smaller than in the case of shearing the alumina particles. In the molten metal, oxides are present as films and clusters. ${ }^{20}$ Particles in agglomerates are joined by van der Waals attractive forces. To de-agglomerate them, it is necessary to apply forces which are stronger than the attractive 
Table I. The FDPA of alumina particles before and after the HSM processing

\begin{tabular}{lccc}
\hline & \multicolumn{3}{c}{ Frequency distribution $(\%)$} \\
\cline { 2 - 4 } Particle area $\left(\boldsymbol{\mu ~ m}^{\mathbf{2}}\right)$ & Before shearing & After 4 min shearing & After 10 min shearing \\
\cline { 2 - 4 } 0 & 1 & 26.9 & 50.8 \\
5000 & 7.5 & 15.3 & 16.8 \\
10,000 & 10 & 18.6 & 10.1 \\
15,000 & 8.5 & 9.1 & 7.1 \\
20,000 & 11.5 & 9.5 & 5.4 \\
\hline
\end{tabular}

forces. In the model system, we have applied shear forces to solid alumina particles bound by much stronger ion bonds.

In the case of the van der Waals forces, the attractive part of the bond potential is represented by $r^{-6}$ (where $r=$ the distance between the both charges' localization). ${ }^{21}$ The force decreases rapidly when the distance increases, thus this force is known as a short-range force. The van der Waals bond is the weakest of all bond types, with a strength between $0.01 \mathrm{eV}$ and $0.1 \mathrm{eV}$ per bond. ${ }^{22,23}$

The aluminum oxide molecules are bound by ionic bonds. The bond energy is typically about 8$10 \mathrm{eV},{ }^{24,25}$ which means that in the model situation we are breaking bonds about 100-1000 times stronger than those expected to bond oxide films and agglomerates in the melt.

Unfortunately, it is difficult to predict the exact values of the forces which join the agglomerates and films together, as they depend on local and temporary conditions such as the presence of dipoles and the distance between them, as well as the number of dipoles in the agglomerates. Instead of predictions, we can refer to real shearing effects. Previous experiments with melts ${ }^{11-14}$ indicated that the shearing forces applied were strong enough to break the agglomerate oxides which resulted in a decrease of grain size. Besides those experimental observations, Men et al. ${ }^{26}$ used both experiments and theoretical modeling to investigate the mechanisms of grain refinement by intensive melt shearing. They found that intensive melt shearing can effectively disperse $\mathrm{MgO}$ films into further individual particles. The $\mathrm{MgO}$ particle density was three orders of magnitude higher than those without shearing. Men et al. ${ }^{26}$ attributed the refining effect of intensive melt shearing to the significantly increased refining efficiency of the naturally occurring $\mathrm{MgO}$ particles. The time necessary to shear metallic oxide agglomerates in the melts is unknown, but computer simulations indicate that only one pass will be effective enough for oxide dispersion. 27 Taking this prediction into account, the shearing time will be optimal when all the liquid passes through the head at least once. That means that the time should be at least equal to the time necessary to perform full mixing of the liquid, plus the time necessary to flow all the liquid through the
Table II. Grain sizes of an Al-3\%Mg alloy in dependence on the time of shearing

\begin{tabular}{lc}
\hline Time of shearing (min) & Average grain size $(\boldsymbol{\mu m})$ \\
\cline { 1 - 1 } 1 & $490 \pm 34$ \\
3 & $410 \pm 31$ \\
5 & $310 \pm 22$ \\
8 & $310 \pm 35$ \\
10 & $320 \pm 28$ \\
\hline
\end{tabular}

head. As the predictions of the model cannot give us an exact forecast about the mandatory time for effective oxide shearing, we obtained these results experimentally as presented below. The physical modeling discussed above allows us to conclude that the most important changes happen probably in first $4 \mathrm{~min}$ and no later than after $10 \mathrm{~min}$ of processing. The time necessary for the de-agglomeration of relatively weak bonds should be shorter or equal to $4 \mathrm{~min}$ since this time was sufficient for the breaking of much stronger ion bonds.

\section{Shearing Influence on the Grain Size of Al Alloys}

There are some correlations available for the open impellers to predict the mixing time if the impeller design and the physical properties of the fluid are known, ${ }^{28}$ but no such data exist for the high-shear rotor-stator devices. The main practical question is what is the minimum or optimum time needed to disperse and distribute oxides in a vessel? When we operate with a specific fluid, the key point is to check the time influence on the real process. In metallurgy, the measurements of the homogeneity system during liquid metal processing are difficult. Instead of the real-time homogeneity measurements, we can compare the results of the oxide dispersion. There are good indications that the dispersed oxides act as nucleation sites which are translated to the reduced grain size ${ }^{7-14}$ Thus, a number of grains and differences in their sizes can give us information on how effective is the processing by the HS device for a chosen time. To establish the critical time, we checked the processing times of the $\mathrm{Al}-3 \% \mathrm{Mg}$ alloy in the range of $1-10 \mathrm{~min}$. The 

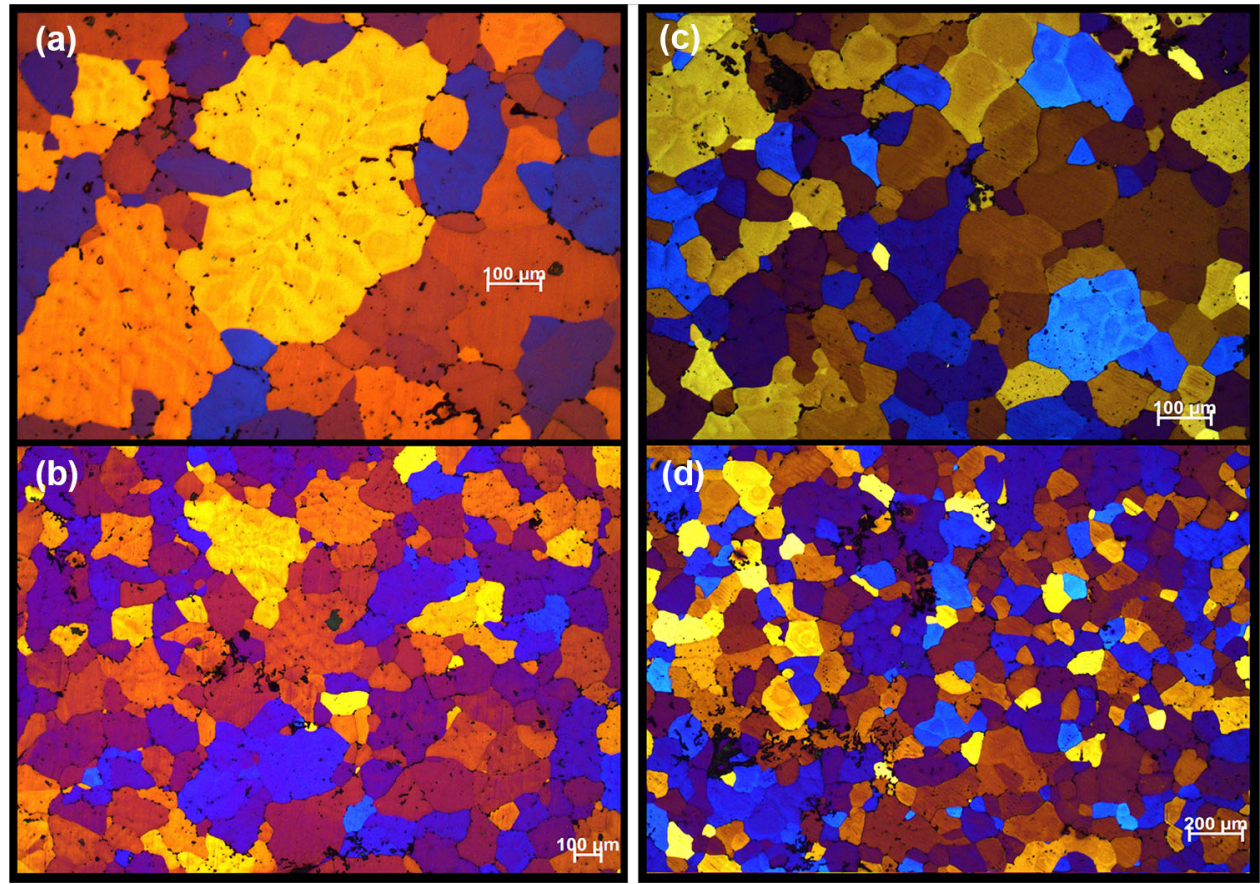

Fig. 2. The grain size of an Al-3\%Mg alloy decreases with the shearing time (images are shown for two magnifications); (a, b) after 2 min of shearing, (c, d) after 4 min of shearing.

average grain size is presented in Table II as the function of the shearing time at $3000 \mathrm{rpm}$. The used $N$ is smaller than in the model experiment but is enough to achieve the full mixing mode ${ }^{29}$ since the head diameter is bigger.

After some specific time, the grain size reached saturation. We observed the change in the grain size only in the first few minutes ( $<5$ min). A number of similar experiments confirmed the repeatability of these results: after 2 min of shearing, the rounded average grain size was about $178 \pm 23 \mu \mathrm{m}$ and decreased to $156 \pm 20 \mu \mathrm{m}$ after $3 \mathrm{~min}$. The fourth minute of shearing determined a further grain size reduction to $97 \pm 1 \mu \mathrm{m}$. Although the grain size was different (maybe due to the specific impurity level or the local cooling rate), the trend in the grain size dependence on the shearing time was the same, i.e. 4 min resulted in full processing.

Figure 2 shows the grain structures observed after $2 \mathrm{~min}$ and $4 \mathrm{~min}$ of HSM shearing. The considerable grain refining is observed after about 4 min of shearing in fully agitated conditions. Thus, the minimum time of dispersion and distribution of oxide clusters for this experimental setting is expected between the 3rd and 4th min of shearing.

We can assume that, in fully agitated conditions, the oxide films and clusters should be dispersed and the number of agglomerates should decrease up to the moment when it reaches the equilibrium. In the ideal situation, when there will be no more clusters to be dispersed, the liquid with the oxide will just be stirred without big variations in the local homogeneity. ${ }^{19}$ Unfortunately, the exact predictions of the time necessary to break the bonds of clusters and films are not yet available. The Tong ${ }^{27}$ simulation indicates that only one pass of the fluid through the head is required. However, the experimentally found time equivalent to $4 \mathrm{~min}$ reflects not only the time necessary for de-agglomeration but it is the time needed for full agitation as well as the time required for all of the fluid to pass through the head enough times to cause cluster fragmentation. Thus, this experimentally observed value can be treated as a guideline for a user, but the full optimization of the process needs more research, for example, the comprehensive computer simulation of the cluster breakages.

\section{CONCLUDING REMARKS}

Effective dispersion is dependent on the flow behavior and requires full vessel agitation to be kept going for over $4 \mathrm{~min}$ as that is the time when the process probably reaches the steady state. The proposed model indicates this time as being sufficient to achieve good fragmentation results. The liquid metal experiments confirm that grain sizes decrease significantly after 4 min of shearing in fully agitated conditions.

\section{ACKNOWLEDGEMENTS}

Allocation of the equipment in the BCAST, Brunel University London is highly appreciated. The first author is grateful for Ph.D. study funding from Institute of Materials and Manufacturing, Brunel University London. The authors would like to acknowledge Prof Z. Fan who initiated this research. 


\section{OPEN ACCESS}

This article is distributed under the terms of the Creative Commons Attribution 4.0 International License (http://creativecommons.org/licenses/by/4.0/ ), which permits unrestricted use, distribution, and reproduction in any medium, provided you give appropriate credit to the original author(s) and the source, provide a link to the Creative Commons license, and indicate if changes were made.

\section{REFERENCES}

1. G. Scamans, H. Li, and Z. Fan, ICAA13, ed. H. Weiland, A. Rollett, and W. Cassada (Hoboken: Wiley, 2012), pp. 13951400 .

2. H.T. Li, G. Scamans, and Z. Fan, Mater. Sci. Forum 765, 97 (2013).

3. N.R. Green and J. Campbell, Mater. Sci. Eng. A A137, 261 (1993).

4. J. Mi, R. Harding, and J. Campbell, Met. Mater. Trans. A 35A, 2893 (2004)

5. C. Nyahumwa, N. Green, and J. Campbell, Trans. Am. Foundrym. Soc. V 106, 215 (1998).

6. Q. Wang, D. Apelian, and L. Dos, J. Light Met. 1, 73 (2001).

7. Z. Fan, Solidification Science and Technology, ed. Z. Fan and I. Stone (London: Brunel University Press, 2011), pp. 29-44.

8. H. Men and Z. Fan, IOP Conf. Ser. Mater. Sci. Eng. 27, 012007 (2012).

9. S. Tzamtzis, H. Zhang, M. Xia, N. Hari Babu, and Z. Fan, Mater. Sci. Eng. A 528, 2664 (2011).

10. H.T. Li, Y. Wang, M. Xia, Y. Zuo, and Z. Fan, Solidification Science and Technology, ed. Z. Fan and I. Stone (London: Brunel University Press, 2011), pp. 93-110.

11. J. Patel, Y. Zuo, and Z. Fan, Proceedings of the 2013 International Symposium on Liquid Metal Processing and Casting, ed. M.J. Krane, A. Jardy, R. Williamson, and J. Beaman (Hoboken: Wiley, 2013), p. 291.
12. Y. Zuo, B. Jiang, Y. Zhang, and Z. Fan, IOP Conf. Ser. Mater. Sci. Eng. 27, 012043 (2012).

13. H.T. Li, Y. Wang, and Z. Fan, Acta Mater. 60, 1528 (2012).

14. H.T. Li, M. Xia, Y. Zuo, and Z. Fan, J. Cryst. Growth 314 285 (2011).

15. D. Gupta and A. Lahiri, Metall. Mater. Trans. B 27B, 757 (1996).

16. D. Xu, W. Jones Jr., and J. Evans, Metall. Mater. Trans. B 29B, 1281 (1998).

17. L. Zhang, S. Taniguchi, and K. Matsumoto, Ironmak. Steelmak. 29, 326 (2002).

18. L. Zhang, S. Taniguchi, and K. Matsumoto, Metall. Mater. Trans. B 38B, 63 (2007).

19. V. Atiemo-Obeng, W. Penney, and P. Armenante, Handbook of Industrial Mixing Science and Practice, ed. E. Paul, V. Atiemo-Obeng, and S. Kresta (Hoboken: Wiley, 2004), pp. 556-557.

20. J. Campbell, Castings, 2nd ed. (Oxford: ButterworthHeinemann, 2015), pp. 20-32.

21. G. Vaughan, Carbon Molecules and Materials, ed. R. Setton, P. Bernier, and S. Lefrant (Boca Raton: CRC Press, 2002), p. 201.

22. J. Roesler, H. Harders, and M. Baeker, Mechanical Behaviour of Engineering Materials (Berlin: Springer, 2007), p. 20.

23. B. Smirnov, Cluster Ions and van der Waals Molecules (Boca Raton, CRC Press, 1992), pp. IX, X, 1-27, 185.

24. Y. Il'inskii and L. Keldysh, Electromagnetic Response of Material Media (Berlin: Springer, 2013), pp. 185-189.

25. R. John, Solid State Physics, 1e (New Delhi: McGraw-Hill Education, 2014) (Table 1.1).

26. H. Men, B. Jiang, and Z. Fan, Acta Mater. 58, 6526 (2010).

27. M. Tong, The presentation at the project meeting for RecycAl, BCAST, 30 Mar 2016, Brunel University, London.

28. K. Carpenter, Handbook of Batch Process Design, ed. P. Sharratt (London: Blackie/Chapman and Hall, 1997), p. 107.

29. A. Dybalska, Understanding and Development of High Shear Technology for Liquid Metals Processing, Ph.D. thesis (Brunel University, London, 2016), pp. 148-154, 203-207. 